\title{
Acidente provocado por picada de abelhas como causa de morte de cães
}

\author{
Bee sting as cause of death in dogs
}

\author{
Rafael Almeida Fighera ${ }^{\text {** Tatiana Mello de Souza }}{ }^{\mathrm{I}}$ \\ Claudio Severo Lombardo de Barros ${ }^{\mathrm{II}}$
}

\begin{abstract}
Acidentes causados por himenópteros são freqüentes em animais domésticos, mas apenas raramente reportados na literatura. Este relato descreve seis casos fatais de reação tóxica sistêmica decorrente de acidente por abelhas (Apis mellifera) em cães. Os principais sinais clínicos foram icterícia e hemoglobinúria. Outros achados incluíram anorexia, apatia, vômito, diarréia e dispnéia. Na necropsia, cinco dos seis cães apresentavam icterícia, fígado vermelho-alaranjado, rins intensamente enegrecidos e urina com coloração semelhante à do vinho tinto. Na histologia, havia necrose hepática centrolobular e nefrose hemoglobinúrica, lesões típicas de crise hemolítica intravascular.
\end{abstract}

Palavras-chave: doenças de cães, picada de abelha, reação tóxica sistêmica, anemia hemolítica, toxicologia, patologia.

\section{ABSTRACT}

Hymenopteran stinging events are frequent cause of disease and death in domestic animals, but rarely reported in the literature. This paper reports six cases of envenomation by bee (Apis mellifera) sting in dogs with fatal outcome. The main clinical signs were icterus and hemoglobinuria. Other findings included anorexia, apathy, vomiting, diarrhea, and dyspnea. Necropsy findings in five dogs included icterus, redorange discoloration of the liver, dark-red kidneys with an redwine aspect to the urine. Histologically, there were centrolobular necrosis in the liver and hemoglobinuric nephosis, typical lesions of intravascular hemolysis.

Key words: diseases of dogs, bee sting, bee envenomation, hemolytic anemia, toxicology, pathology.
Acidentes por insetos da ordem Hymenoptera ocorrem com freqüência em seres humanos (LANGLEY \& MORROW, 1997; LANGLEY, 2005) e animais domésticos (SCHIMIDT \& HASSEN, 1996). No Brasil, eles incluem principalmente agravos com abelhas (Apis mellifera), marimbondos (Polistes spp.) e mamangavas (Bombus spp.) (CARDOSO et al., 2003). Esses acidentes têm importância médica e veterinária porque, em indivíduos dessa ordem zoológica, há aparelho inoculador de veneno (ferrão verdadeiro), que é derivado de um ovopositor modificado, o qual possui glândulas veneníferas anexas (VETTER et al., 1999).

A doença clínica manifestada por humanos e animais atacados por abelhas pode resultar tanto de uma reação de hipersensibilidade por apenas uma picada (reação alérgica), quanto de envenenamento por poucas (reação tóxica local ou reação habitual) ou múltiplas ferroadas (reação tóxica sistêmica) (CARDOSO et al., 2003).

Em humanos, a reação tóxica sistêmica caracteriza-se inicialmente por manifestações dermatológicas típicas de intoxicação histamínica, pode levar a um quadro de choque e culminar em morte (VETTER et al., 1999). Essa manifestação clínica é decorrente da inoculação de substâncias químicas vasodilatadoras presentes no veneno desses insetos, principalmente do peptídeo desgranulador de

'Programa de Pós-graduação em Medicina Veterinária, Universidade Federal de Santa Maria (UFSM), 97105-900, Santa Maria, RS, Brasil. E-mail: anemiaveterinaria@yahoo.com.br. *Autor para correspondência.

"Laboratório de Patologia Veterinária, Departamento de Patologia, UFSM, Santa Maria, RS, Brasil. 
mastócitos (DE LIMA \& BROCHETTO-BRAGA, 2003).

Além dessa forma de apresentação, ataques massivos por abelhas freqüentemente cursam com rabdomiólise e crise hemolítica (FRANÇA et al., 1994). Quando isso ocorre, a mioglobinúria e a hemoglobinúria desenvolvidas pelos pacientes causam necrose tubular e, conseqüentemente, insuficiência renal aguda (VETTER et al., 1999).

Em animais, a reação tóxica sistêmica tem sido observada como cursando com vômito, diarréia, sinais de choque (SCHIMIDT \& HASSEN, 1996) e dificuldade respiratória em decorrência de síndrome da angústia respiratória aguda (SARA) (WALKER et al., 2005). Nos cães, além dos quadros de choque e SARA, casos de crise hemolítica também têm sido descritos (WYSOKE et al., 1990; NOBLE \& ARMSTRONG 1999). Embora acidentes em animais causados por abelhas sejam ocasionalmente observados na rotina diagnóstica e divulgados pela mídia, existem apenas poucos casos descritos na literatura científica.

Entre 1965 e 2004, foram necropsiados 4.844 cães no Laboratório de Patologia da Universidade Federal de Santa Maria (UFSM). Desses, seis (0,12\%) morreram em decorrência de envenenamento por abelhas. Esses cães eram provenientes do Hospital Veterinário da UFSM ou de clínicas particulares e apresentavam histórico de terem sido atacados por enxames de abelhas. Clinicamente, todos os cães afetados apresentaram icterícia 24 a 72 horas após o agravo. Cinco cães apresentaram urina com coloração escura, que, posteriormente, na necropsia, confirmou ser decorrente da presença de hemoglobina. Outros achados clínicos incluíram anorexia (5/6), apatia (3/6), vômito (3/6), diarréia (2/6) e dispnéia (2/6). Todos esses cães foram tratados e cinco deles morreram em um intervalo de dois a cinco dias após o acidente. Um dos cães recuperou-se parcialmente, mas morreu após 35 dias do acidente.

Em dois dos seis cães afetados, foi realizado hemograma que demonstrou anemia (24 a $27 \%$ de hematócrito e 2,8 a 3,1 x $10^{6}$ eritrócitos $\mathrm{mm}^{-3}$ ) macrocítica (85,7 a 87,1 fl de VCM) com anisocitose, policromasia e metarrubricitemia moderada. Os níveis de hemoglobina (10,5 a 12,2. $\mathrm{g} \mathrm{dl}^{-1}$ ) eram bastante elevados em relação ao hematócrito e à contagem de eritrócitos, o que causou uma falsa hipercromia (43,7\% a 45,2\% de CHCM). O plasma estava marrom-escuro, em decorrência da grande quantidade de hemoglobina livre (hemoglobinemia) (Figura 1A).

$\mathrm{Na}$ necropsia, cinco dos seis cães apresentavam icterícia de toda a carcaça, fígado vermelho-alaranjado, rins intensamente enegrecidos e urina com coloração semelhante à do vinho tinto (Figura
1B). Nesses cinco cães, podiam ser observados múltiplos ferrões encravados na pele e abelhas (Apis mellifera) mortas por entre o pelame, no saco conjuntival, na cavidade oral, no esôfago e no estômago. Na histologia, em todos esses casos havia necrose hepática centrolobular e nefrose hemoglobinúrica (Figura 1C), lesões típicas de crise hemolítica intravascular. O cão que morreu 35 dias após o agravo tinha os rins pálidos e várias lesões extrarenais de uremia. Na histologia, havia necrose tubular aguda acentuada com sinais de regeneração das células epiteliais que revestem os túbulos contornados proximais.

Embora acidentes por abelhas ocorram com certa freqüência em animais domésticos, principalmente em cães e eqüinos (SCHIMIDT \& HASSEN, 1996), parece haver certo desconhecimento na patogênese dessa toxicose. Em todos os casos aqui descritos, os veterinários interpretaram a manifestação clínica desenvolvida pelos cães como choque anafilático. Entretanto, nenhum desses cães apresentou qualquer evidência clínica ou patológica de reação alérgica.

Após serem atacados pelos enxames de abelhas, todos os cães demonstraram sinais clínicos que sugeriam crise hemolítica intravascular. Além disso, nos dois casos em que foi realizado o hemograma, os achados hematológicos foram típicos desse tipo de alteração eritrocítica. Distúrbios hemolíticos têm sido incriminados como uma das principais complicações dos acidentes por abelhas em cães (SCHIMIDT \& HASSEN, 1996). Nesses casos, ocorre lesão da membrana eritrocítica mediada por alguns constituintes do veneno, como as fosfolipases e a melitina, o que desencadeia a hemólise intravascular (WYSOKE et al., 1990; NOBLE \&ARMSTRONG 1999).

A hemoglobinúria desenvolvida pelos cães parece ter sido a causa da necrose tubular aguda vista nesses casos, à semelhança do que é descrito na literatura (WYSOKE et al., 1990; NOBLE \& ARMSTRONG, 1999). Entretanto, mais recentemente, estudos têm demonstrado que talvez haja uma ação direta de alguns constituintes do veneno das abelhas nas células do epitélio tubular renal (DOS REIS et al., 1998). Esses estudos têm sido conduzidos a fim de se entender porque alguns acidentes por abelhas em humanos cursam com necrose tubular aguda mesmo quando não há crise hemolítica ou rabdomiólise e, conseqüentemente, hemoglobinúria e mioglobinúria.

A presença dos ferrões encravados na pele e de abelhas mortas por entre o pelame e no interior do trato digestivo permitiu confirmar a observação dos proprietários e clínicos de que os cães haviam sido atacados por enxames de abelhas. Por fim, os achados 


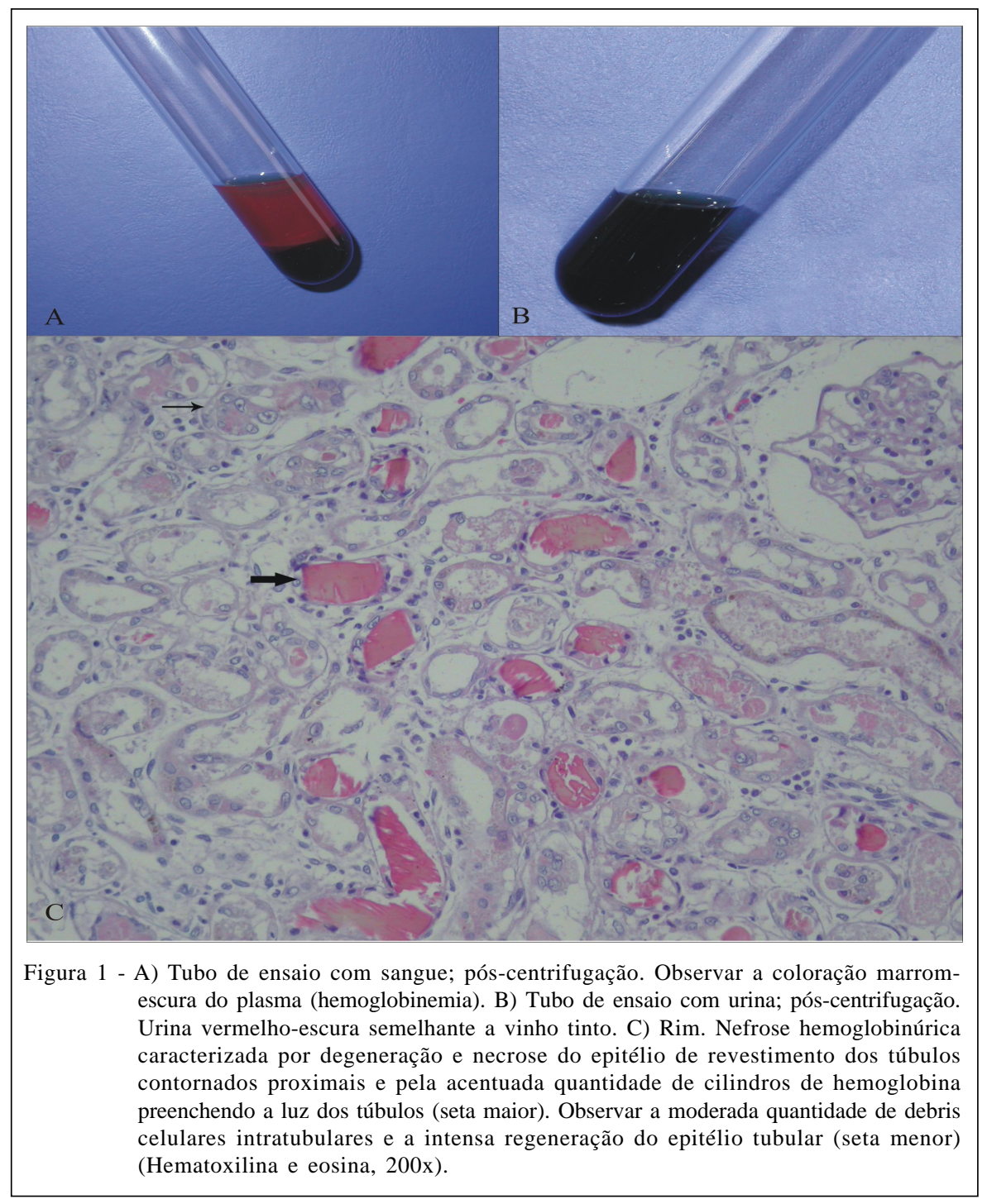

de necropsia confirmaram que, em cinco casos, ocorreu crise hemolítica intravascular fatal. Em um dos casos, em que o cão morreu após 35 dias do acidente, os achados clínicos e hematológicos foram contundentes em estabelecer a crise hemolítica. Além disso, havia lesões de insuficiência renal aguda de origem tóxica, provavelmente como conseqüência da hemoglobinúria desenvolvida após o acidente.

Os aspectos clínicos, hematológicos e patológicos encontrados nesses seis casos permitiram estabelecer que o acidente por abelhas ocasionou crise hemolítica fatal. O conhecimento dos sinais clínicos e das lesões dessa forma de apresentação clinicopatológica dos acidentes por abelhas é importante, pois permite diferenciar aqueles pacientes que manifestam reação alérgica dos que apresentam reação tóxica, um aspecto necessário para a adoção de medidas terapêuticas e para o estabelecimento do prognóstico.

\section{AGRADECIMENTOS E APRESENTAÇÃO}

Ao professor David Driemeier, chefe do Laboratório de Patologia Veterinária da Universidade Federal do Rio Grande do Sul (UFRGS), pela confecção da figura 1C. Este trabalho é parte da tese de doutorado do primeiro autor.

\section{REFERÊNCIAS}

CARDOSO, J.L.C. et al. Animais peçonhentos no Brasil biologia, clínica e terapêutica dos acidentes. São Paulo: Sarvier, 2003. 468p.

DE LIMA, M.R.; BROCHETTO-BRAGA, M.R. Hymenoptera venom review focusing on Apis mellifera. Journal of Venomous Animals Toxins including Tropical Diseases, v.9, n.2, p.149-162, 2003.

Ciência Rural, v.37, n.2, mar-abr, 2007. 
DOS REIS, M.A. et al. Acute renal failure in experimental envenomation with Africanized bee venom. Renal Failure, v.20, n.1, p.39-51, 1998.

FRANÇA, F.O. et al. Severe and fatal mass attacks by "killer" bees (Africanized honey bees - Apis mellifera scutellata) in Brazil: clinicopathological studies with measurement of serum venom concentrations. Quarterly Journal of Medicine, v.87, n.5, p.269-282, 1994.

LANGLEY, R.L. Animal-related fatalities in the United Statesan update. Wilderness \& Environmental Medicine, v.16, n.2, p.67-74, 2005.

LANGLEY, R.L.; MORROW, W.E. Deaths resulting from animal attacks in the United States. Wilderness \& Environmental Medicine, v.8, n.1, p.8-16, 1997.

NOBLE, S.J.; ARMSTRONG, P.J. Bee sting envenomation resulting in secondary immune-mediated hemolytic anemia in two dogs. Journal of the American Veterinary Medical Association, v.214, n.7, p.1021, 1999.

SCHIMIDT, J.O.; HASSEN, L.V.B. When africanized bees attack: what your clients should know. Veterinary Medicine, v.10, p.923-928, 1996.

VETTER, R.S. et al. Mass envenomations by honey bees and wasps. Western Journal of Medicine, v.170, n.4, p.223227, 1999.

WALKER, T. et al. Imaging diagnosis: acute lung injury following massive bee envenomation in a dog. Veterinary Radiology \& Ultrasound, v.46, n.4, p.300-303, 2005.

WYSOKE, J.M. et al. Bee sting-induced haemolysis, spherocytosis and neural dysfunction in three dogs. Journal of the South African Veterinary Association, v.61, n.1, p.29-32, 1990. 